\title{
Radio Frequency Electronics on Plastic
}

\author{
- Revolution by Flexible Solution
}

\author{
F. Ellinger, K. Ishida, R. Shabanpour, \\ T. Meister, B. K. Boroujeni, C. Carta \\ Chair for Circuit Design and Network Theory \\ Technische Universität Dresden \\ Dresden, Germany \\ Frank.Ellinger@tu-dresden.de
}

\author{
L. Petti, G. A. Salvatore, G. Tröster \\ Electronics Laboratory \\ Swiss Federal Institute of Technology \\ Switzerland, Zurich
}

\author{
N. Münzenrieder \\ Sensor Technology Research \\ Center \\ University of Sussex \\ Sussex, UK
}

\begin{abstract}
In this paper the recent progress of active high frequency electronics on plastic is discussed. This technology is mechanically flexible, bendable, stretchable and does not need any rigid chips. Indium Gallium Zinc Oxide (IGZO) technology is applied. At $2 \mathrm{~V}$ supply and gate length of 0.5 $\mu \mathrm{m}$, the thin-film transistors (TFTs) yield a measured transit frequency of $138 \mathrm{MHz}$. Our scalable TFT compact simulation model shows good agreement with measurements. To achieve a sufficiently high yield, TFTs with gate lengths of around $5 \mu \mathrm{m}$ are used for the circuit design. A Cherry Hopper amplifier with $3.5 \mathrm{MHz}$ bandwidth, $10 \mathrm{~dB}$ gain and $5 \mathrm{~mW}$ dc power is presented. The fully integrated receiver covering a plastic foil area of $3 \times 9 \mathrm{~mm}^{2}$ includes a four stage cascode amplifier, an amplitude detector, a baseband amplifier and a filter. At a de current of $7.2 \mathrm{~mA}$ and a supply of $5 \mathrm{~V}$, a bandwidth of $2-20 \mathrm{MHz}$ and a gain beyond $15 \mathrm{~dB}$ were measured. Finally, an outlook regarding future advancements of high frequency electronics on plastic is given.
\end{abstract}

Keywords: High frequency electronics, wireless communications, transmitter, receiver, organic, thin film and large area electronics (TOLAE), amplifiers

\section{INTRODUCTION}

Today's electronics is implemented on rigid boards, substrates or chips. However, many objects in daily-life are not rigid - they are bendable, stretchable and even foldable. Examples are paper, tapes, our body, our skin and textiles. Until today there is a gap between electronics and bendable daily-life items. This gap can be bridged by thin film, organic and large area electronics (TOLAE) offering bendability, light weight, ultra thin dimensions, transparency, stretchability, suitability for large areas, low costs, etc. [1].

The applicability of TOLAE for wireless communications is limited by the low speed associated with the low mobilities of the used flexible semiconductor materials. However, recently, the speed of TOLAE was massively increased. Based on IGZO material yielding a mobility of $15 \mathrm{~cm}^{2} / \mathrm{Vs}$, a transit frequency $\left(\mathrm{f}_{\mathrm{t}}\right)$ of approximately $140 \mathrm{MHz}$ was demonstrated for TFTs [2].

978-1-4673-9492-5/15/\$31.00 C2015 IEEE
These recent achievements indicate a novel promising research area: Wireless communication systems fully integrated on a single ultra-thin, bendable and flexible sheet of plastic or paper. Hence, conventional rigid circuit boards or chips would not be required any more.

System and circuit architectures have to be optimized taking into account the limited operation frequencies, bandwidths and device counts of flexible technologies.

Due to the advantages of mechanical flexibility, bendability, strechability and even transparency, TOLAE has the potential for a technical revolution for specific wireless applications, where mechanical flexibility is more important than performance such as high data rates.

Examples for such applications are as follows: data communications for simple sensor and actuator networks, medical and on-body devices, fully flexible broadcast radios, smart item tracking, single-use items, and devices integrated in textiles.

One specific application is envisioned in Fig. 1. A future band-aid or wound tape could include an organic sensor and a flexible transceiver which can send wirelessly information about the healing status, possible infections, etc. to a server station enabling further processing and examination by a doctor.

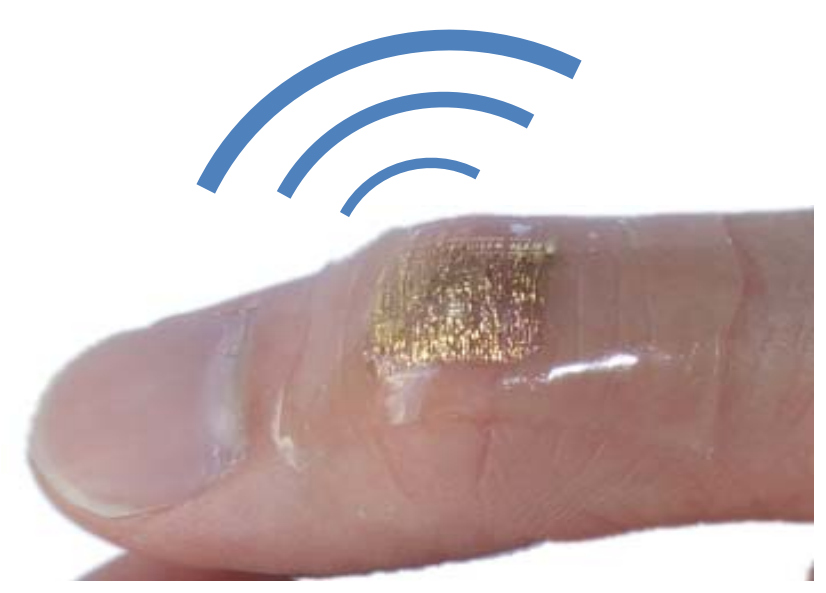

Fig. 1. Radio band-aid: example of an application for flexible and stretchable wireless transceivers on thin sheet of plastic 
Our paper is structured as follows: The international state of the art is summarized in Section II. Sections III and IV describe the used IGZO technology and the TFT models, respectively. A Cherry Hopper RF amplifier and a fully integrated wireless receiver chip are presented in Sections $\mathrm{V}$ and VI. Proposals for advancements as well as conclusions are given in Sections VII and IIX.

\section{STATE OF THE ART}

In the following we summarize key works in the area of RF TFTs, TOLAE and related materials.

Based on IGZO technology, we have designed a TFT compact model [3], several RF amplifiers [4] and a fully integrated receiver [5].

A record speed was achieved with nanocrystalline Zinc Oxide $(\mathrm{ZnO})$ TFTs [6]. Devices with $1.2 \mu \mathrm{m}$ gate length $\left(l_{g}\right)$ yield a $f_{t}$ of $2.45 \mathrm{GHz}$ and a maximum frequency of oscillation $\left(f_{\max }\right)$ of $7.45 \mathrm{GHz}$ at $10 \mathrm{~V}$ supply. However, these TFTs are fabricated on a non-flexible silicon substrate. Nevertheless, this work shows the promising potential of TFTs.

At $3 \mathrm{~V}$, an $\mathrm{f}_{\mathrm{t}}$ of $180 \mathrm{MHz}$, a transconductance of 7.5 $\mathrm{mS} / \mathrm{mm}$ and a mobility of $14.5 \mathrm{~cm}^{2} / \mathrm{Vs}$ were reported for IGZO TFTs [7]. But these devices are just realised on glass. IGZO TFTs with $1_{\mathrm{g}}$ down to $20 \mathrm{~nm}$ structured by focussed ion beam (FIB) approaches have been fabricated on rigid $\mathrm{Si}$ substrate [8], but neither circuits are fabricated nor RF performance parameters are given.

Several ring oscillator circuits were published. A $\mathrm{ZnO}$ based ring oscillator with $31 \mathrm{~ns}$ propagation delay was reported in [9].

A ring oscillator with signal delays as short as $230 \mathrm{~ns}$ per stage was demonstrated using organic FETs [10].

A $3.3 \mathrm{~V} \mathrm{6-bit} 100 \mathrm{kS} / \mathrm{s}$ current-steering digital to analogue converter (DAC) using organic TFTs on glass was presented in [11].

To improve the speed, carbon nanotube transistors were applied for logic circuits with the vision to be used for large area electronics [12]. A switching time of only 12 ns was achieved corresponding to a speed of around $100 \mathrm{MHz}$.

In [13] an operational amplifier and a digital-to-analogue converter were presented. Both circuits are fabricated using amorphous silicon TFTs. The operational amplifier achieves a gain of $42.5 \mathrm{~dB}$ and a unity gain frequency of $30 \mathrm{kHz}$ at a supply voltage of $25 \mathrm{~V}$.

An 8 bit organic microprocessor with 4000 transistor was implemented on a plastic foil [14]. An integrated organic Schottky diode rectifier operating at $13.56 \mathrm{MHz}$ was reported in [15]. An organic thin-film RFID tag with 128 bit and a data rate of $1.5 \mathrm{~kb} / \mathrm{s}$ operating at $13.56 \mathrm{MHz}$ and $24 \mathrm{~V}$ were published [16-17]. Magnetic fields generated by the reader are used for data transmission.

Transition metal dichalcogenides materials have been proposed for the realisation of future devices. Mobilities of $200 \mathrm{~cm}^{2} / \mathrm{Vs}$ for $\mathrm{MoS}_{2}$ [18] and up to $250 \mathrm{~cm}^{2} / \mathrm{Vs}$ for tungsten diselenide $\left(\mathrm{WSe}_{2}\right)$ [19] were reported. Hence, flexible transistors with $f_{t}$ values above $1 \mathrm{GHz}$ may be feasible in the future.
Transistors based on $\mathrm{ZnO}$ nanowires and $\mathrm{WS}_{2}$ nanotubes were investigated in [20]. The $\mathrm{ZnO}$ nanowire side-gated transistors revealed a very promising mobility of $928 \mathrm{~cm}^{2} / \mathrm{Vs}$.

Transfer printing techniques capable of transferring entire devices from one substrate to another have e.g. been published in [21]. A simple and reliable transfer printing process for solvent-free deposition of organic semiconducting materials using a polydimethylsiloxane stamp was developed [22]. This process has the potential to realise high mobility films, very small gaps between metal electrodes and hence fast FETs with nm gate length. Nanoimprint is well-suited for the realisation of flexible devices and nanometer-sized structures over large areas. Diameters up to $200 \mathrm{~mm}$ have been demonstrated [23]. Smallest patterns imprinted are a few nanometres [24].

Several microwave components were realised using potentially printable techniques, e.g. a $2.4 \mathrm{GHz}$ antenna [25], tuneable ferroelectric filters on organic substrates [26], barium strontium titanate varactors [27], all-inkjet printed capacitors [28] and ferroelectric capacitors [29].

Very fast organic PIN-diodes and rectifier circuits suited for frequencies up to $300 \mathrm{MHz}$ were demonstrated [30].

The feasibility of three dimensional (3-D) integrated organic circuits such as ring oscillators [31] and steerable printed antennas [32] were shown.

An 8-10 GHz ink-jet printed phase shifter circuit with $342^{\circ}$ phase shift range using ferroelectric material (bariumstrontium-titanat) was presented in [33].

Companies such as Varta and Enfucell have developed ultra-thin primary and secondary batteries on thin-film and organic substrates. Theses flexible batteries can be used to supply the flexible circuits and systems.

\section{UsED DeVICE TECHNOLOGY}

In Fig. 2, the structure of the applied IGZO TFTs is shown [2]. A polyimide substrate with $50 \mu \mathrm{m}$ thickness is used. The process offers 3 metal layers for interconnections. At $2 \mathrm{~V}$ drain source voltage, an $\mathrm{f}_{\mathrm{t}}$ of $138 \mathrm{MHz}$ was measured for the self-aligned TFTs with $1_{\mathrm{g}}=0.5 \mu \mathrm{m}$. This high speed is maintained even at bending radii down to $3.5 \mathrm{~mm}$. The measurements are plotted in Fig. 3.

To achieve a good yield and moderate process variations, TFTs with $1_{\mathrm{g}}=5 \mu \mathrm{m}$ are used for the design of the amplifier and receiver presented in Sections VI and VII.

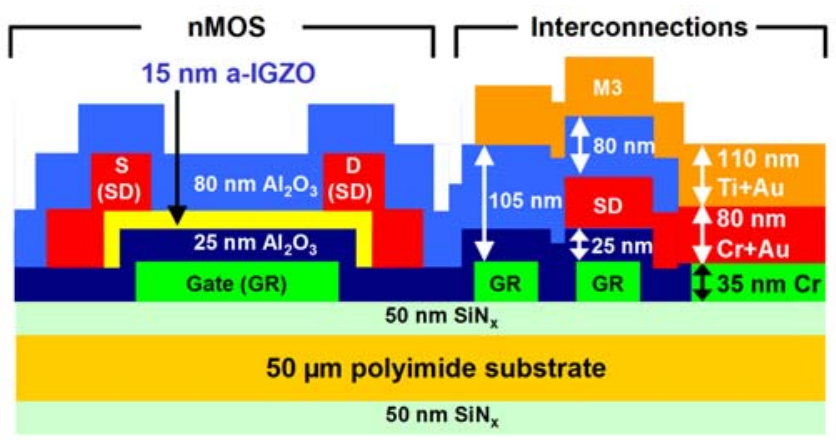

Fig. 2. Device structure of the IGZO TFTs 


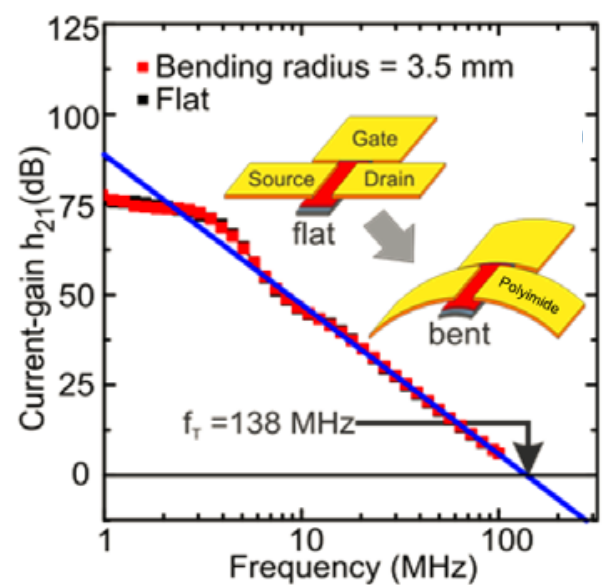

Fig. 3. Measured transit frequency of the IGZO TFTs with $1_{g}=0.5 \mu \mathrm{m}$

\section{DeVICE ModelLing}

A Rensselaer Polytechnic Institute amorphous TFT model template is applied for the TFT compact modeling in ADS. The models are extracted by fitting with measured DC, AC and S-parameter data. As shown in Fig. 4, a very good agreement between measured and modelled DC characteristics is achieved. The model is well scalable for $l_{g}$ values between $50 \mu \mathrm{m}$ and $5 \mu \mathrm{m}$. The RF accuracy will be verified in Section VI.
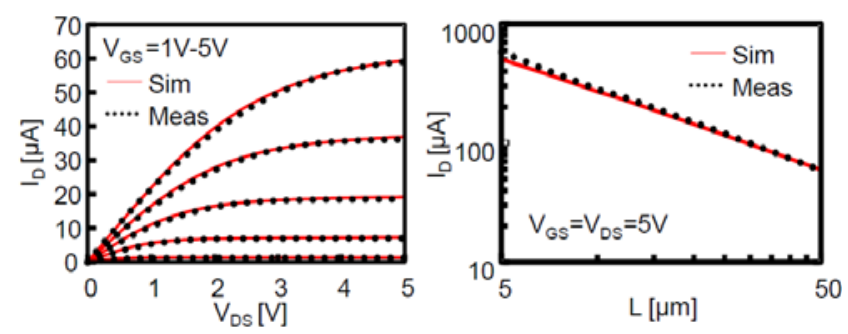

Fig. 4. Comparison of measurements and simulations based on our SPICE Level 3 model of the IGZO TFTs

\section{RF AMPLIFIER}

We have designed several amplifier ICs to test the RF circuit properties of the IGZO devices and the accuracy of our TFT models. One example is shown in Fig. 5, which is based on the Cherry Hopper concept [4].
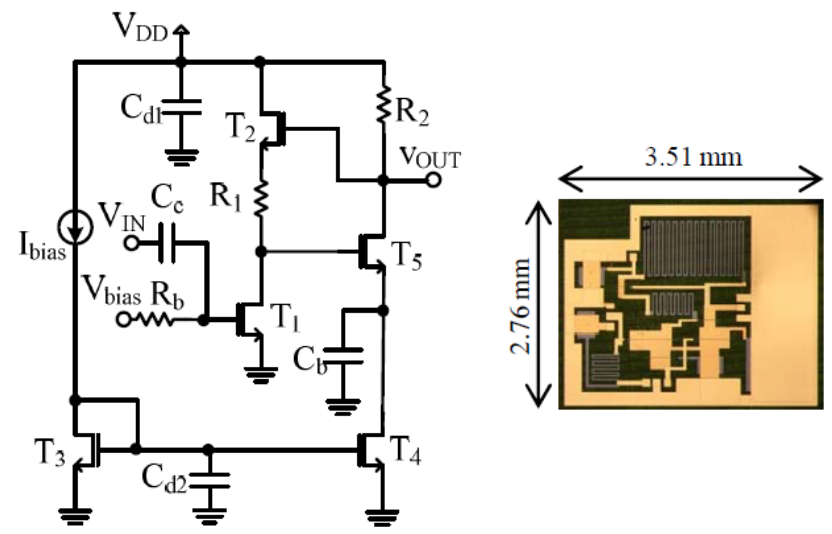

Fig. 5. Circuit schematics and chip photo of the IGZO Cherry Hopper RF amplifier
As depicted in Fig. 6 a gain of $10 \mathrm{~dB}$ and a bandwidth of 3.5 MHz were measured. The RF simulations applying our TFT model show good agreement with measurements.

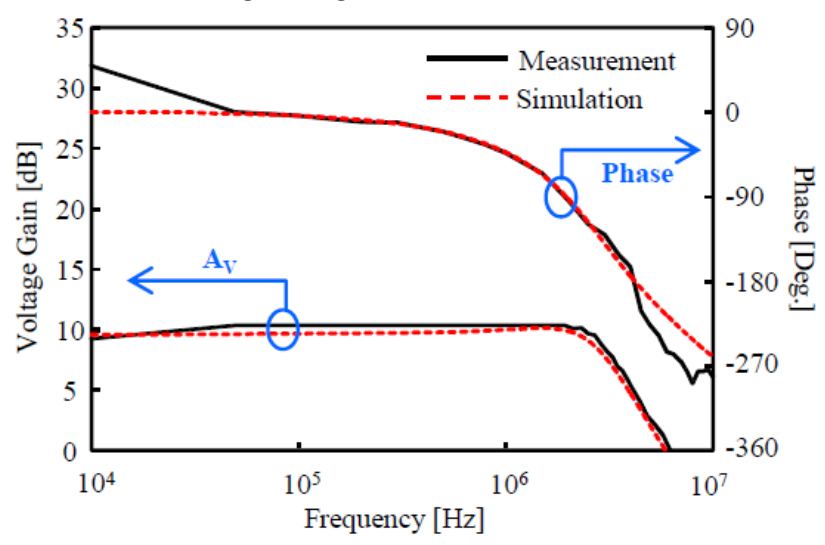

Fig. 6. Voltage gain of the IGZO Cherry Hopper RF amplifier

\section{WIRELESS RECEIVER}

We have designed a fully integrated IGZO receiver applying amplitude modulation (AM) [5]. To our knowledge this is the first fully integrated receiver on plastic reported to date. The circuit consists of a four-stage cascode amplifier at the RF input, an amplitude detector based on a source follower, and a common source circuit for the baseband amplification. The circuit schematics and the chip photo are depicted in Fig. 7. As illustrated in Fig. 8, the measured conversion gain is very flat and exceeds $15 \mathrm{~dB}$ at a carrier frequency ranging from 2 to 20 $\mathrm{MHz}$. The $3 \mathrm{~dB}-$ bandwidth of the baseband signal covers $400 \mathrm{~Hz}$ to $10 \mathrm{kHz}$. This band is comparable to the voice spectrum and also suitable for low-rate data communication. The functionality of the receiver is shown in Fig. 9. The receiver draws a moderate current of $7.2 \mathrm{~mA}$ from a $5 \mathrm{~V}$ supply and requires a plastic foil area of $3 \times$ $9 \mathrm{~mm}^{2}$.

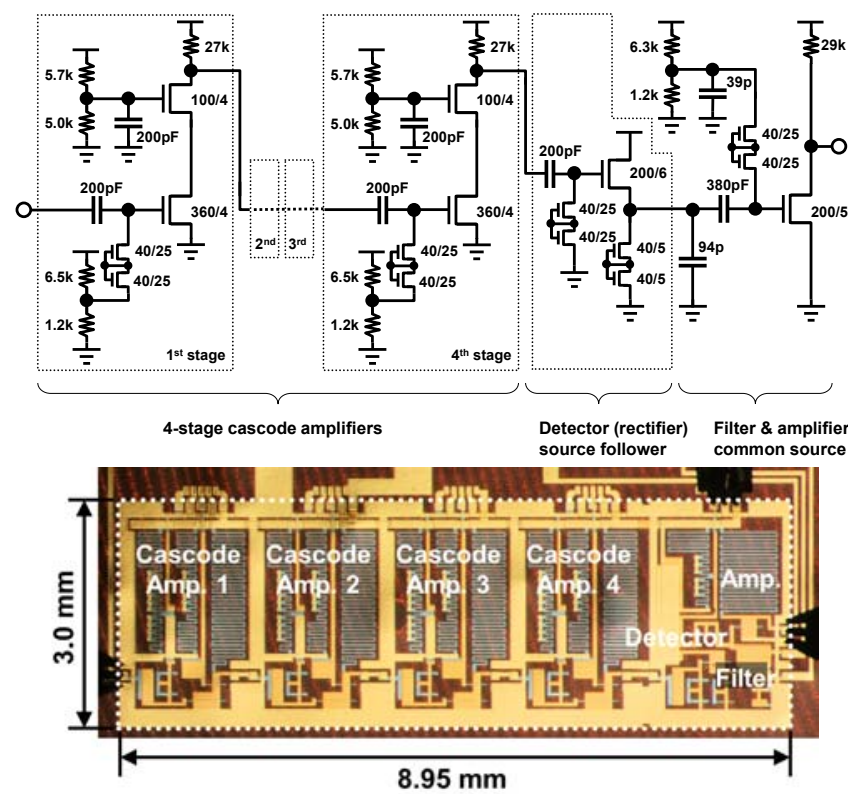

Fig. 7. Schematics and chip photo of the fully integrated IGZO receiver, area: $3 \times 9 \mathrm{~mm}^{2}$ 


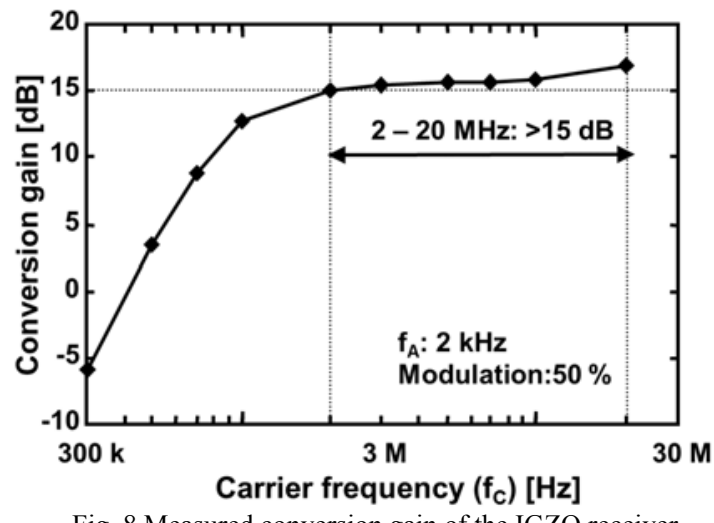

Fig. 8 Measured conversion gain of the IGZO receiver

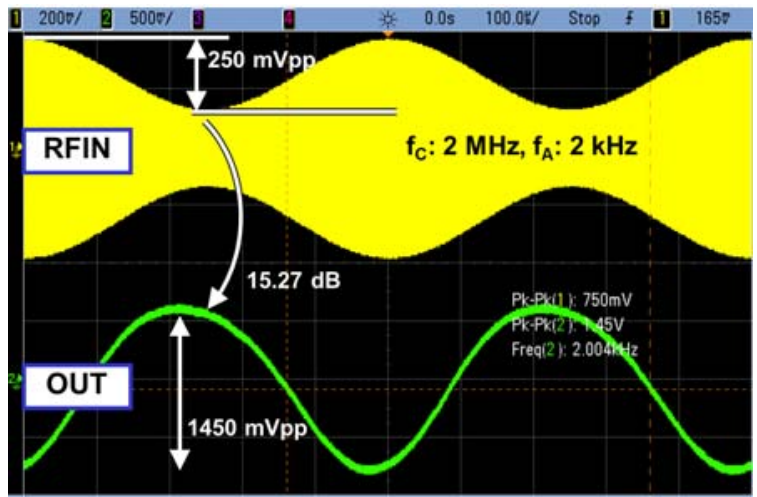

Fig. 9. Measured demodulated waveform of IGZO receiver

\section{ADVANCED APPROACHES}

The transit frequency of TFTs can be approximated by

$$
f_{t}=\frac{g_{m}}{2 \pi C_{g s}} \propto \frac{\mu}{1_{g}\left(1_{g}+1_{o v}\right)},
$$

with transconductance $g_{m}$, gate source capacitance $C_{g s}$, mobility $\mu$, gate length $1_{g}$, and gate to source/drain overlap $1_{\mathrm{ov}}$. This equation reveals the following examples for potential speed optimisations:

\section{a. Decrease of gate length}

By means of vertical transistor structures as shown in Fig. 10, the distance between the drain and the source, and hence $1_{\mathrm{g}}$, can be reduced. An $1_{\mathrm{g}}$ of $300 \mathrm{~nm}$ was realised in our latest work [34].

\section{b. Increase of mobility}

The mobilities can e.g. be increased by using 2D semiconductors such as Molybdenum Disulfide which can provide mobilities up to $200 \mathrm{~cm}^{2} / \mathrm{Vs}$. For further info we refer to [35]. For comparison, the IGZO technology used for the circuits presented in this paper provides a mobility of $15 \mathrm{~cm}^{2} / \mathrm{Vs}$.

\section{c. Circuits}

Architectures have to be applied which can reach high frequencies with low speed devices. Concepts architectures with frequency multipliers can be considered. Here, passive organic diodes which show a speed up to $300 \mathrm{MHz}$ could be applied in the RF frontend section [30]. To boost the gain and frequencies, controlled positive feedback is interesting.

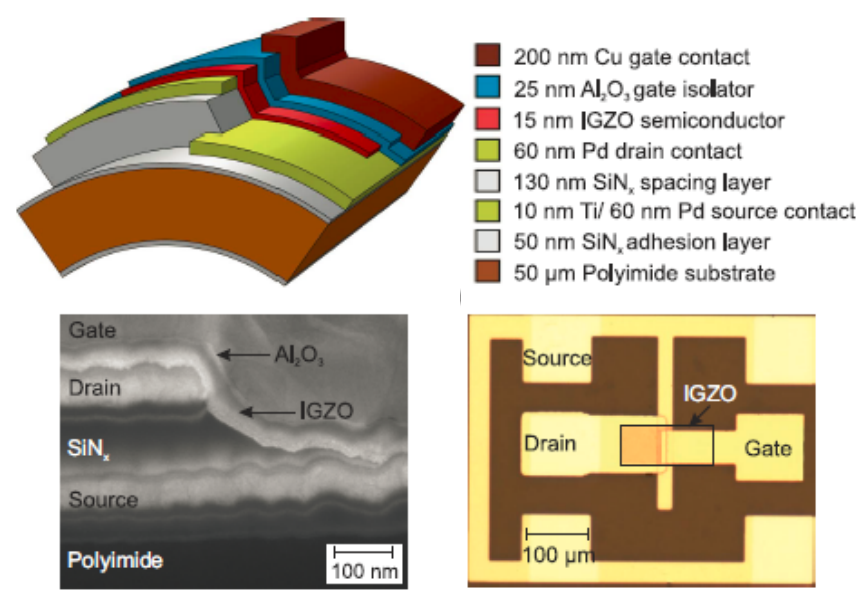

Fig. 10. Flexible vertical IGZO TFTs with $1_{\mathrm{g}}=300 \mathrm{~nm}$

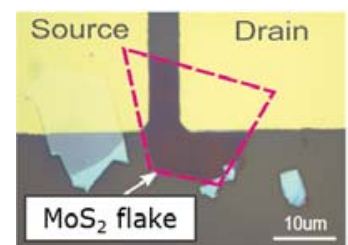

Fig. 11. Molybdenum Disulfide enables higher mobilities

\section{IIX. CONCLUSIONS}

In this paper, the recent performances of RF devices and systems on plastic were reviewed. IGZO TFTs yield an $f_{t}$ of $138 \mathrm{MHz}$ at $0.5 \mu \mathrm{m} \mathrm{g}_{\mathrm{g}}$. Good TFT compact modelling is possible based on a Rensselaer Polytechnic TFT model template. With $5 \mu \mathrm{m} 1_{g}$, amplifiers with a bandwidth of $3.5 \mathrm{MHz}$ and a gain of $10 \mathrm{~dB}$ were measured at $5 \mathrm{~mW} \mathrm{dc}$ power. A fully integrated AM 2-20 $\mathrm{MHz}$ receiver was demonstrated which provides $15 \mathrm{~dB}$ gain and consumes only $36 \mathrm{~mW}$.

These results show that it is possible to realise communication systems on a simple sheet of plastic and without any rigid chips. This could be a revolution for applications such as simple low-cost sensor and actuator networks, medical and on-body systems, fully flexible broadcast radios, smart item tracking, and devices integrated in textiles.

However, to improve the market potential of these TOLAE technologies for RF and wireless communications, the speed has to be further improved. Corresponding proposals for future improvements were outlined.

\section{Let's go for a revolution by flexible RF solutions!}

\section{ACKNOWLEDGEMENTS}

The authors want to thank the EU project FLEXIBILITY (no. 287568), the DFG priority program FFlexCom (SPP 1796), the DFG funded Center for Advancing Electronics Dresden and the DFG project "Vertikale organische Transistoren für Hochfrequenzanwendungen und niedrige Betriebsspannungen" for funding, cooperation and inspiration. 


\section{REFERENCES}

[1] N. Münzenrieder, G. Cantarella, C. Vogt, L. Petti, L. Büthe, G.A. Salvatore, Y. Fang, R. Andri, Y. Lam, R. Libanori, D. Widner, A.R. Studart, and G. Tröster, Stretchable and Conformable Oxide ThinFilm Electronics. Adv. Electron. Mater., 1, 3, 2015

[2] N. Munzenrieder, L. Petti, C. Zysset, T. Kinkeldei, T. G. A. Salvatore, G. Troster, Flexible Self-Aligned Amorphous InGaZnO Thin-Film Transistors With Submicrometer Channel Length and a Transit Frequency of $135 \mathrm{MHz}$, IEEE Transactions on Electron Devices, Vol. 60, No. 9, pp. 2815-2820, Sept. 2013

[3] C. Perumal, K. Ishida, R. Shabanpour, B. K. Boroujeni, L. Petti, N. S. Munzenrieder, G.A. Salvatore, C. Carta, G. Troster, F. Ellinger, A Compact a-IGZO TFT Model Based on MOSFET SPICE Level $=$ 3 Template for Analog/RF Circuit Designs, IEEE Electron Device Letters, Vol. 34, No. 11, pp. $1391-1393,2013$

[4] R. Shabanpour, T. Meister, K. Ishida, B. K. Boroujeni, C. Carta, U. Jörges, F. Ellinger, L. Petti, N. Münzenrieder, G.A. Salvatore, G. Tröster, Cherry-Hooper Amplifiers with $33 \mathrm{~dB}$ Gain at $400 \mathrm{kHz}$ BW and $10 \mathrm{~dB}$ Gain at $3.5 \mathrm{MHz}$ BW in Flexible Self-Aligned aIGZO TFT Technology, Intern. Symposium on Intelligent Signal Processing and Communication Systems, pp. 271 - 274, Dec. 2014

[5] K. Ishida, R. Shabanpour, T. Meister, B. K. Boroujeni, C. Carta, L. Petti, N. Münzenrieder, G. A. Salvatore, G. Tröster, and F. Ellinger, 15 dB Conversion Gain, $20 \mathrm{MHz}$ Carrier Frequency AM Receiver in Flexible a-IGZO TFT Technology with Textile Antennas, Symposia on VLSI Technology and Circuits, June 2015

[6] B. Bayraktaroglu, K. Leedy, and R. Neidhard, High-Frequency ZnO Thin-Film Transistors on Si Substrates, Electron Device Letters, vol. 30, no. 9, pp 946-948, Sept. 2009

[7] Y. L. Wang, L. N. Covert, T. J. Anderson, W. Lim, J. Lin, S. J. Pearton, D. P. Norton, J. M. Zavada, and F. Ren, RF characteristics of room temperature deposited small gate dimension indium zinc oxide TFTs, Electrochem. Solid State Lett., vol. 11, no. 3, pp. H60H62, Jan. 2008

[8] L. Haojun, Amorphous Indium Gallium Zinc Oxide Based Thin Film Transistors and Circuits. Dissertation North Carolina State University 2013.

[9] J. Sun, D. A. Mourey, D. Zhao, S. K. Park, S. F. Nelson, D. H. Levy, D. Freeman, P. Cowdery-Corwan, and T. N. Jackson, ZnO thin-film transistor ring oscillators with 31-ns propagation delay, IEEE Electron Device Lett., vol. 29, no. 7, pp. 721-723, July 2008.

[10] F. Ante, D. Kälblein, T. Zaki, U. Zschieschang, K. Takimiya, M. Ikeda, T. Sekitani, T. Someya, J. N. Burghartz, K. Kern, H. Klauk, Contact Resistance and Megahertz Operation of Aggressively Scaled Organic Transistors, Small, vol. 8, no. 1, pp. 73-79, Jan. 2012

[11] T. Zaki, F. Ante, U. Zschieschang, J. Butschke, F. Letzkus, H. Richter, H. Klauk, J. N. Burghartz, A 3.3 V 6-Bit 100 kS/s CurrentSteering Digital-to-Analog Converter Using Organic P-Type ThinFilm Transistors on Glass, IEEE Journal of Solid-State Circuits, Vol. 47, no. 1, pp. 292 - 300, January 2012

[12] H. Ryu, D. Kälblein, O. G. Schmidt, H. Klauk, Unipolar Sequential Circuits Based on Individual-Carbon-Nanotube Transistors and Thin-Film Carbon Resistors, ACS Nano, vol. 5, no. 9, pp. 75257531, Sept. 2011

[13] Yi-Chuan Tarn, Po-Chih Ku, Hsieh-Hung Hsieh, and Liang-Hung Lu: An Amorphous-Silicon Operational Amplifier and Its Application to a 4-Bit Digital-to Analog Converter, IEEE Journal Solid-State Circuits, vol. 45, no. 5, pp. 1028-1035, May 2010

[14] K. Myny, E. van Veenendaal, G.H. Gelinck, J. Genoe, W. Dehaene, P. Heremans, An $8 \mathrm{~b}$ organic microprocessor on plastic foil, IEEE Intern. Solid-State Circuits Conf., pp. 322 - 324, Feb. 2011

[15] K. Myny, S. Steudel, P. Vicca, Peter, J. Genoe, P. Heremans, An integrated double half-wave organic Schottky diode rectifier on foil operating at $13.56 \mathrm{MHz}$, Applied Physics Letters, vol. 93, no. 9, pp. 093305/1-3, 2008

[16] K. Myny, et al. A 128b organic RFID transponder chip, including Manchester encoding and ALOHA anti-collision protocol, operating with a data rate of $1529 \mathrm{~b} / \mathrm{s}$, ISSCC 2009

[17] K. Myny, S. Steudel, P. Vicca, M.J. Beenhakkers, N.A.J.M. van Aerle, G.H. Gelinck, J. Genoe, W. Dehaene, P. Heremans, Plastic circuits and tags for $13.56 \mathrm{MHz}$ radio-frequency communication. Solid-State Electronics, vol. 53, pp. 1220-1226, 2009
[18] B. Radisavljevic, A. Radenovic, J. Brivio, V. Giacometti, A. Kis, Single-layer MoS2 transistors, Nature Nanotechnology, vol. 6, pp. 147-150, Jan. 2011

[19] Q. H. Wang, K. Kalantar-Zadeh, A. Kis, et. al., Electronics and optoelectronics of two-dimensional transition metal dichalcogenides, Nature Nanotechnology 7, pp. 699-712, Nov. 2012

[20] Husnu Emrah Unalan, et. al., ZnO Nanowire and WS2 Nanotube Electronics, IEEE Transactions on Electron Devices, vol. 55, no. 11, pp. 2988-3000, 2008

[21] D. R. Hines, V. W. Ballarotto, E. D. Williams, Y. Shao, and S. A. Solin, "Transfer printing methods for the fabrication of flexible organic electronics, Journal of Applied Physics, vol. 101, no. 2, p. 024503, Jan. 2007

[22] M. Bareiß, F. Ante, D. Kälblein, G. Jegert, C. Jirauschek, G. Scarpa, B. Fabel, E. Nelson, G. Timp, U. Zschieschang, H. Klauk, W. Porod, and P. Lugli, High-Yield Transfer Printing of MetalInsulator-Metal Nanodiodes, ACS Nano, vol. 6, no. 3, pp. 28532859, March 2012

[23] N. Chaix, C. Gourgon, C. Perret, S. Landis, T. Leveder, Nanoimprint lithography processes on $200 \mathrm{~mm} \mathrm{Si}$ wafer for optical application, J. Vacuum Science \& Techn., vol. B25, pp. 2346-2351, Nov/Dec 2007

[24] S.Y. Chou, P.R. Renstrom, W. Zhang, L. Guo, L. Zhuang, Sub-10 $\mathrm{nm}$ imprint lithography and applications, J. Vacuum Science and Techn., vol. B15, pp. 2897-2904, Nov/Dec 1997

[25] V. K. Palukuru, K. Sanoda, V. Pynttäri, T. Hu, R. Mäkinen, M Mäntysalo, J. Hagberg, and H. Jantunen, Inkjet Printed RF Structures on BST-Polymer Composites: An Application of a Monopole Antenna for $2.4 \mathrm{GHz}$ Wireless Local Area Network Operation, Int. Journal of Applied Ceramic Technology, vol. 8, pp. 940-946, 2011.

[26] S. Courreges, B. Lacroix, A. Amadjikpe, S. Phillips, Z. Zhao, K. Choi, A. Hunt, and J. Papapolymerou, Back-to-back tunable ferroelectric resonator filters on flexible organic substrates, IEEE Trans. Ultrasonics, Ferroelectrics and Frequency Control, vol. 57, pp. 1267-1275, 2010

[27] S. Ya, S. Ebadi, P. Wahid, and G. Xun, Tunable and flexible Barium Strontium Titanate (BST) varactors on Liquid Crystal Polymer substrates, IEEE Intern. Microwave Symposium, 2012

[28] J. Lim, J. Kim, Y. J. Yoon, H. Kim, H. G. Yoon, S.-N. Lee, and J. Kim, All-inkjet-printed Metal-Insulator-Metal (MIM) capacitor, Current Applied Physics, vol. 12, pp. e14-e17, 2012

[29] U. S. Bhansali, M. A. Khan, and H. N. Alshareef, Electrical performance of polymer ferroelectric capacitors fabricated on plastic substrate using transparent electrodes, Organic Electronics, vol. 13, pp. 1541-1545, 2012

[30] H. Kleemann, S. Schumann, U. Jörges, F. Ellinger, K. Leo and B. Lüssem, Organic pin-diodes approaching ultra-high-frequencies, Organic Electronics, vol. 13, no. 6, pp. 1114-1120, June 2012

[31] A. C. Hübler, G. C. Schmidt, H. Kempa, K. Reuter, M. Hambsch, and M. Bellmann, Three-dimensional integrated circuit using printed electronics, Organic Electronics, vol. 12, pp. 419-423, March 2011

[32] R. Zichner, R. R. Baumann: 3-D transponder antennas for future SHF RFID applications, Advances in Radio Science, vol. 9, pp. 401-405, 2011

[33] M. Sazegar, Z. Yuliang, H. Maune, C. Damm, Z. Xianghui, J. Binder, and R. Jakoby, Low-Cost Phased-Array Antenna Using Compact Tunable Phase Shifters Based on Ferroelectric Ceramics, IEEE Trans. Microwave Theory and Techniques, vol. 59, pp. 12651273, 2011

[34] L. Petti, A. Frutiger, N. Münzenrieder, G. A. Salvatore, L. Büthe, C. Vogt, G. Cantarella, G. Tröster, Senior Member, Flexible QuasiVertical In-Ga-Zn-O Thin-Film Transistor With 300-nm Channel Length, IEEE Electron Devices Letters, Vol. 36, No. 5, pp. $475-$ 477, May 2015

[35] G. A. Salvatore, N. Münzenrieder, C. Barraud, L. Petti, C. Zysset, L. Büthe, K. Ensslin, and G. Tröster, Fabrication and Transfer of Flexible Few-Layers MoS2 Thin Film Transistors to Any Arbitrary Substrate, ACS Nano, 7, 10, 2013 